\title{
Microstructural characterization of nickel subjected to dynamic plastic deformation
}

\author{
Luo, Z.P.; Mishin, Oleg; Zhang, Yubin; Zhang, H.W.; Lu, K.
}

Published in:

Scripta Materialia

Link to article, DOI:

10.1016/j.scriptamat.2011.11.022

Publication date:

2012

Document Version

Early version, also known as pre-print

Link back to DTU Orbit

Citation (APA):

Luo, Z. P., Mishin, O., Zhang, Y., Zhang, H. W., \& Lu, K. (2012). Microstructural characterization of nickel subjected to dynamic plastic deformation. Scripta Materialia, 66(6), 335-338.

https://doi.org/10.1016/j.scriptamat.2011.11.022

\section{General rights}

Copyright and moral rights for the publications made accessible in the public portal are retained by the authors and/or other copyright owners and it is a condition of accessing publications that users recognise and abide by the legal requirements associated with these rights.

- Users may download and print one copy of any publication from the public portal for the purpose of private study or research.

- You may not further distribute the material or use it for any profit-making activity or commercial gain

- You may freely distribute the URL identifying the publication in the public portal

If you believe that this document breaches copyright please contact us providing details, and we will remove access to the work immediately and investigate your claim. 


\title{
Microstructural characterization of nickel subjected to dynamic plastic deformation
}

\author{
Z.P. Luo ${ }^{1}$, O.V. Mishin ${ }^{2}$, Y.B. Zhang ${ }^{2}$, H.W. Zhang ${ }^{1}$, K. Lu ${ }^{1}$ \\ ${ }^{1}$ Shenyang National Laboratory for Materials Science, Institute of Metal Research, Chinese Academy \\ of Sciences, 110016 Shenyang, China \\ ${ }^{2}$ Danish-Chinese Center for Nanometals, Materials Research Division, Risø National Laboratory for \\ Sustainable Energy, Technical University of Denmark, DK-4000, Roskilde, Denmark
}

\begin{abstract}
Average microstructural parameters and the extent of microstructural heterogeneity in nickel deformed at a high strain rate have been characterized quantitatively and compared to those after compression at a quasi-static strain rate. The microstructure in the high strain rate sample was found to be more refined and less heterogeneous than that in the sample compressed at a low strain rate. The greater refinement in the former sample was achieved due to subdivision by a high frequency of finely-spaced low-angle boundaries.
\end{abstract}

Keywords: Dynamic plastic deformation, nickel, deformation structure, dislocation boundaries, misorientation 
Significant interest in nanostructured materials produced by heavy deformation is a strong motivation for developing new straining techniques. Equal channel angular extrusion (ECAE), accumulated roll bonding (ARB), high-pressure torsion (HPT) and several other novel techniques $[1,2]$ have been developed to accumulate very large strains and thus to refine the length scale of the microstructure. In contrast to these techniques of severe plastic deformation, dynamic plastic deformation (DPD) [3,4] utilizes high strain rates $\left(\sim 10^{2}-10^{3} \mathrm{~s}^{-1}\right)$, which has been shown to produce considerable structural refinement at comparatively low strains. For example, the refinement to the nanometer scale has been achieved in cryogenically DPD-processed copper and in a $\mathrm{Cu}-\mathrm{Al}$ alloy [3-5]. In these materials, the significant refinement was both due to subdivision of the microstructure by dislocation boundaries and due to mechanical twinning.

In high stacking-fault energy (SFE) materials, DPD was also found to reduce the boundary spacing compared to that after low strain rate deformation. However, due to the lack of mechanical twinning, the microstructure in such materials is less refined than that in copper. For example, in pure aluminum deformed by DPD to strains of $1.6-2.4$, the subgrain size was found to be $0.3-0.5 \mu \mathrm{m}$ [6]. To study grain subdivision by dislocation boundaries in a DPD-processed material with a somewhat lower SFE than that for $\mathrm{Al}$, we have chosen to inspect the microstructure in nickel compressed at a high strain rate. Nickel is characterized by an intermediate SFE (128 mJ/m² [7]) compared to those for copper and aluminum (78 and $166 \mathrm{~mJ} / \mathrm{m}^{2}$, respectively [7]) and therefore is particularly suitable for evaluating the effect of SFE on structural parameters in DPD-processed materials. In the present work, both average structural parameters and local heterogeneities of the deformed microstructure in DPD Ni are described quantitatively and compared with those after compression at a quasi-static strain (QSC) rate. 
A recrystallized pure (99.96 wt.\%) nickel sample was used in the present experiment as the initial material. The average grain size was $11 \mu \mathrm{m}$ including annealing twins and $23 \mu \mathrm{m}$ excluding twin boundaries. Two samples were prepared in the form of a cylinder, in which both the height and the diameter of the cylinders were $20 \mathrm{~mm}$. One sample (DPD-sample) was compressed using a dynamic loading technique described in [3,4]. At first the sample was compressed to $8 \mathrm{~mm}$ applying a 2-3 mm reduction per pass, after which a $\varnothing 10 \mathrm{~mm}$ cylinder was machined from the deformed sample to further compress it to a final thickness of $2.1 \mathrm{~mm}$ using a $1 \mathrm{~mm}$ reduction per pass. Another sample (QSCsample) was first deformed at a constant speed of $0.8 \mathrm{~mm} / \mathrm{min}$ to $8 \mathrm{~mm}$ followed by further compression of a machined $\varnothing 10 \mathrm{~mm}$ cylinder to $2.1 \mathrm{~mm}$ at $0.4 \mathrm{~mm} / \mathrm{min}$. This resulted in a total strain of 2.3 for both samples. The strain rate for each DPD-pass was estimated to be $10^{2}-10^{3} \mathrm{~s}^{-1}$, while for the QSC-sample the strain rate was $10^{-3} \mathrm{~s}^{-1}$. It should be mentioned that flat surfaces of the QSC sample were coated with an oil-based lubricant, whereas no lubricant was used for the DPD sample.

The microstructure in the center part of the deformed samples was then investigated using both transmission electron microscopy (TEM) and electron backscatter diffraction (EBSD) techniques. In each case, sections containing both the normal and radial directions of the compressed samples were inspected. A JEOL 2010 transmission electron microscope was used for studying thin foils and measuring boundary misorientations. Misorientations were measured in several regions across 440 and 385 boundaries in the DPD and QSC samples, respectively. Low angle boundaries (LABs) were defined as those between cells with misorientations below $15^{\circ}$. Boundaries with higher misorientations were defined as high angle boundaries (HABs). The EBSD study was conducted in a field emission gun scanning electron microscope equipped with a Channel 5 system and a Nordlys detector. In each 
deformed sample, three regions with a total area of $\sim 2000 \mu \mathrm{m}^{2}$ were mapped with a step size of $30 \mathrm{~nm}$. A step size of $3 \mu \mathrm{m}$ was used for gathering texture information from large sample areas, $2-3 \mathrm{~mm}^{2}$.

An example of the deformed microstructure in the DPD sample, as observed in the transmission electron microscope, is presented in Figure 1, where lamellae separated by extended dislocation boundaries are aligned almost perpendicular to the loading direction (LD). Within a framework for the evolution of deformation structures, such boundaries are classified as geometrically necessary boundaries (GNBs) [8,9]. The lamellae are further subdivided by short incidental dislocation boundaries (IDBs) $[8,9]$. It should be noted that GNBs were not always oriented nearly perpendicular to the LD: extended dislocation boundaries oriented $55-70^{\circ}$ to the $\mathrm{LD}$ were also observed in some grains. In a number of locations, evidence of localized shear was also seen. Deformation twins were not observed in the DPD sample studied in the present experiment.

The average spacing between IDBs, $d_{\mathrm{IDB}}$, in DPD Ni was measured to be $330 \mathrm{~nm}$, while the average spacing between GNBs, $d_{\mathrm{GNB}}$, was $\sim 110 \mathrm{~nm}$ (Table 1). These values are much greater than those in $\mathrm{Cu}$ cryogenically deformed to a similar strain, where a fine average boundary spacing (40 nm) was achieved due to a very high frequency of twin boundaries [3]. The boundary spacings in Ni are however considerably smaller compared to those achieved in Al even after cryogenic DPD [6].

Compared to the DPD compressed $\mathrm{Ni}$ sample, the microstructure of the QSC sample is characterized by greater GNB and IDB spacings, but by a much smaller spacing between HABs (see Table 1). Therefore, the microstructure after DPD is refined by a greater number of boundaries per unit area than in the QSC sample. However, this greater refinement in the DPD sample is achieved predominantly by LABs. The fraction of HABs in this material was only 24\%, whereas in the QSC material the fraction of HABs was higher, 32\% (see Table 1). The difference in the misorientation 
distribution is illustrated in more detail in Fig.2. It is seen that the DPD sample contains a much higher fraction of very low misorientations compared to that in the QSC sample.

The increased frequency of LABs in the DPD sample studied in the present work is not consistent with data of Gurao et al. [10], where the average misorientation and the fraction of HABs in compressed Ni were reported to increase with increasing strain rate. The differing results may reflect certain differences in the way the two compression experiments were conducted, e.g. in their friction conditions, but they may also be due to different measurement approaches. It should be noted that the quantitative data in Ref.[10] were based on an EBSD analysis where very low misorientations were undetected. As shown in the present TEM experiment, the fraction of these misorientations in nickel compressed at a high strain rate can be very significant. For example, the fraction of misorientations below $2^{\circ}$ (a cut-off angle frequently used in EBSD experiments) in our DPD sample was almost 15\% (see Fig.2). It is expected that at comparatively low strains $(\varepsilon=0.7-0.85)$ applied by Gurao et al. the fraction of low angle boundaries ignored by EBSD could be even higher. Besides, statistical information on the boundary character distribution in Ref.[10] was extracted from EBSD data collected with a large step size, $3 \mu \mathrm{m}$. At such a large step size, orientations are likely to be measured in cells that are not immediate neighbors in the deformed microstructure, which in general will lead to an additional bias when average boundary misorientations and HAB fractions are considered [11]. To avoid such uncertainties, only TEM data were used in our work for analyzing the distributions of boundary misorientations. The use of TEM in the present experiment ensures that misorientations were always measured across real boundaries and that even very low misorientation angles were confidently identified. 
The difference in the boundary spacings seen in the DPD sample compared to the QSC sample can be rationalized based on a high density of dislocations produced during high strain rate compression [12,13] that may be responsible for more finely-spaced dislocation boundaries after DPD. Orientation changes during compression of the DPD sample could thus be accommodated by subdivision producing many finely-spaced LABs within fairly broad bands separated by HABs. In the QSC sample, where the spacing between GNBs was considerably greater (see Table 1), subdivision by fewer boundaries necessitated an increased frequency of larger misorientation angles across them. Although the subdivision pattern was different in the two deformed samples, similar final textures developed, where $<110>$ directions were aligned with the compression axis (see Fig.3). Some spread from the $<110>$ texture towards $<113>$ is also seen in Fig.3. This texture is similar to those obtained after heavy compression of pure fcc metals with medium and high SFE values [14,15].

Although the EBSD analysis of deformed materials suffers from the limited angular resolution, it offers a unique possibility of orientation mapping of very large areas and thus is very useful for characterizing deformation heterogeneities with misorientations above the angular resolution limit. To describe the heterogeneity of the deformed microstructure in a quantitative manner, large areas in both DPD and QSC samples were inspected using the EBSD technique. For both samples, the obtained EBSD maps revealed heterogeneous microstructures where clusters of fine lamellae delineated by HABs alternated with broad bands consisting of crystallites characterized by a small orientation difference (see Fig.4). It should be mentioned that boundaries with very low misorientations $\left(<1.5^{\circ}\right)$ are not seen in these EBSD maps.

The area fraction of the different types of alternating structures can be characterized using a partitioning of the EBSD data into subsets containing either predominantly low misorientations or predominantly high misorientations. This approach has been previously applied for characterizing 
heterogeneities in ECAE-deformed samples, where low misorientation regions (LMRs) were distinguished from high misorientation regions (HMRs) [16-18]. Following this previous work, LMRs are defined as areas greater than $2.5 \mu \mathrm{m}^{2}$ surrounded by boundaries $>5^{\circ}$. The remaining areas in the deformed microstructure are HMRs. The result of partitioning is shown in Fig.4a, where white and cyan areas represent LMRs and HMRs, respectively. Note that HABs seen in the white areas separate adjacent LMRs. In the three regions studied in the EBSD experiment the average HMR fraction in the DPD sample was calculated to be $26 \%$. This value is significantly lower than that obtained in the QSC sample, where the HMR fraction was 48\%. Since the DPD sample is characterized by a clear dominance of one type of region (LMRs in this case) with pockets of the other type (HMRs), its microstructure can be considered less heterogeneous than the microstructure of the QSC sample, which contains large areas of either HMRs or LMRs, such that there is almost an equal probability of encountering either a LMR- or HMR-dominating area when a single small region is probed in the microstructure.

In summary, microstructures in the center of two nickel samples processed by either DPD or QSC to a strain of 2.3 have been examined using TEM and EBSD techniques. It is shown that the DPD microstructure was refined by a high frequency of finely-spaced LABs. The microstructure of the low strain-rate QSC sample was less refined, but contained a higher frequency of HABs. Considering that one type of region, LMRs, was clearly dominant in the area inspected in the DPD sample, this microstructure appears less heterogeneous than the microstructure of the QSC sample, where area fractions of LMRs and HMRs were similar.

The authors acknowledge support from the Danish National Research Foundation and the National Natural Science Foundation of China (Grant No. 50911130230) for the Danish-Chinese Center for 
Nanometals. We are grateful to Professor A. Godfrey, Dr. N. Hansen and Dr. J.R. Bowen for useful comments on the manuscript.

[1] R.Z. Valiev, Y. Estrin, Z. Horita, T.G. Langdon, M.J. Zehetbauer, Y.T. Zhu, JOM 58 (2006) 33.

[2] D.J. Alexander, JMEP 16 (2007) 360.

[3] W.S. Zhao, N.R. Tao, J.Y. Guo, Q.H. Lu, K. Lu, Scripta Mater. 53 (2005) 745.

[4] Y.S. Li, N.R. Tao, K. Lu, Acta Mater. 56 (2008) 230.

[5] C.S. Hong, N.R. Tao, X. Huang, K. Lu, Acta Mater. 58 (2010) 3103.

[6] F. Huang, N.R. Tao, K. Lu, J. Mater. Sci. Technol. 27 (2011) 1.

[7] L.E. Murr, Scripta Metal. 6 (1972) 203.

[8] D.A. Hughes, N. Hansen, Metall. Mater. Trans. A 24A (1993) 2022.

[9] D.A. Hughes, N. Hansen, Acta Mater. 45 (2997) 3871.

[10] N.P. Gurao, R. Kapoor, S. Suwas, Metall. Mater. Trans. A 41A (2010) 2794.

[11] D. Juul Jensen, Ultramicroscopy 67 (1997) 25.

[12] Z.P. Luo, H.W. Zhang, N. Hansen, K. Lu, (2011) unpublished result.

[13] M. Kiritani, T. Sota, T. Tawara, H. Arimura, K. Yasunaga, Y. Matsukawa, M. Komatsu, Radiat. Eff. Defect. Solid. 157 (2002) 53.

[14] H. Hu, Texture 1 (1974) 233.

[15] M.G. Stout, J.A. O’Rourke, Metall. Mater. Trans. A 20A (1989) 125.

[16] O.V. Mishin, A. Godfrey, Metall. Mater. Trans. A 39A (2008) 2923.

[17] O.V. Mishin, J.R. Bowen, Metall. Mater. Trans. A 40A (2009) 1684.

[18] O.V. Mishin, J.R. Bowen, S. Lathabai, Scripta Mater. 63 (2010) 20. 
Table 1. Parameters of the microstructure in Ni deformed by either DPD or QSC. $d_{\mathrm{IDB}}, d_{\mathrm{GNB}}$ and $f_{\mathrm{HAB}}$ were determined using TEM. The other parameters represent EBSD data.

\begin{tabular}{cccccc}
\hline Sample & \multicolumn{2}{c}{ Boundary spacing $(\mu \mathrm{m})$} & \multicolumn{3}{c}{ Fraction (\%) } \\
\cline { 2 - 6 } & $d_{\mathrm{IDB}}$ & $d_{\mathrm{GNB}}$ & $f_{\mathrm{HAB}}$ & $f_{\mathrm{LMR}}$ & $f_{\mathrm{HMR}}$ \\
\hline DPD & 0.33 & 0.11 & 24 & 74 & 26 \\
QSC & 0.43 & 0.18 & 32 & 52 & 48 \\
\hline
\end{tabular}
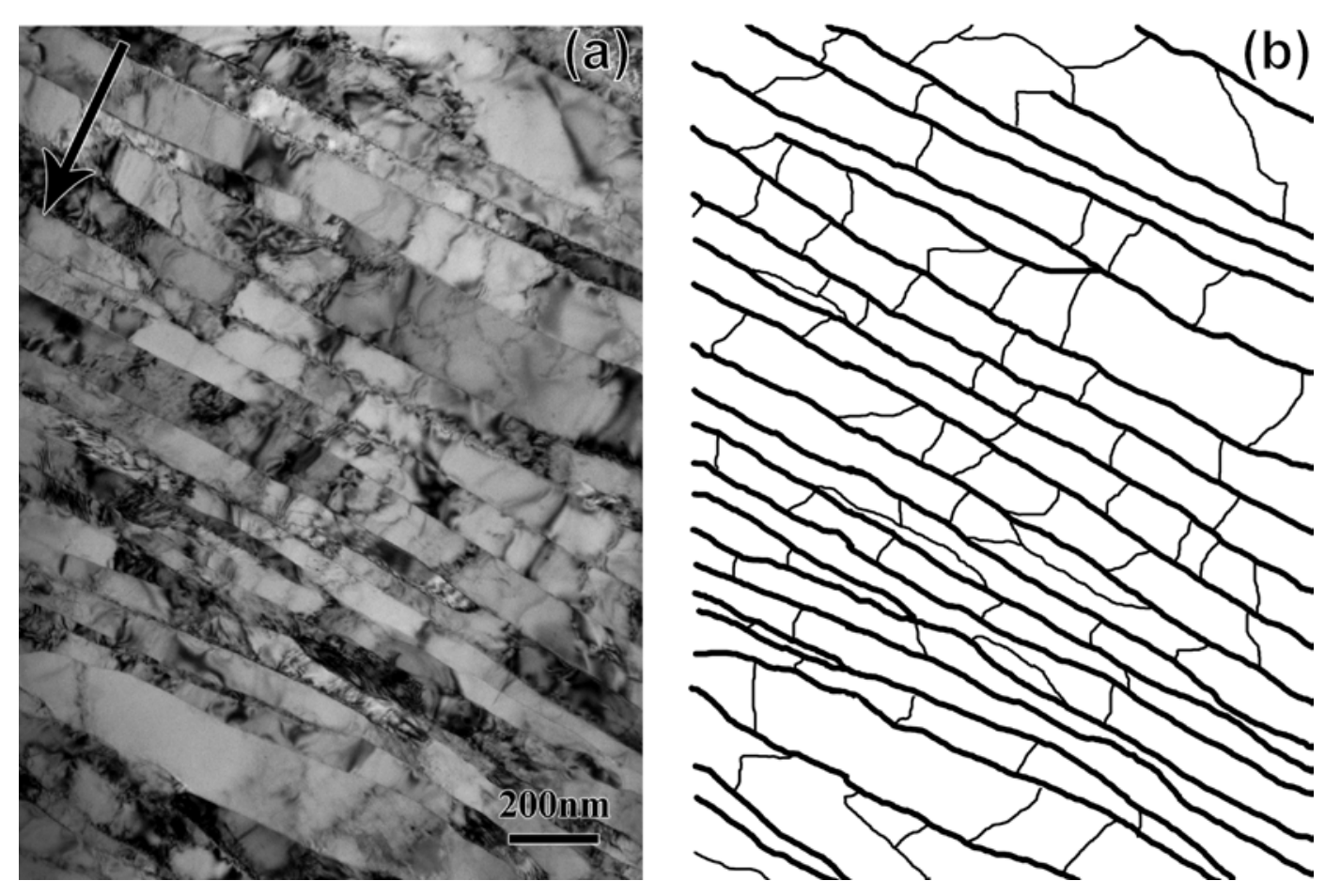

Figure 1. The deformed microstructure in Ni after DPD to a strain of 2.3: (a) TEM image and (b) sketch showing GNBs and IDBs by bold and thin lines, respectively. In (a) the arrow indicates the loading direction. 

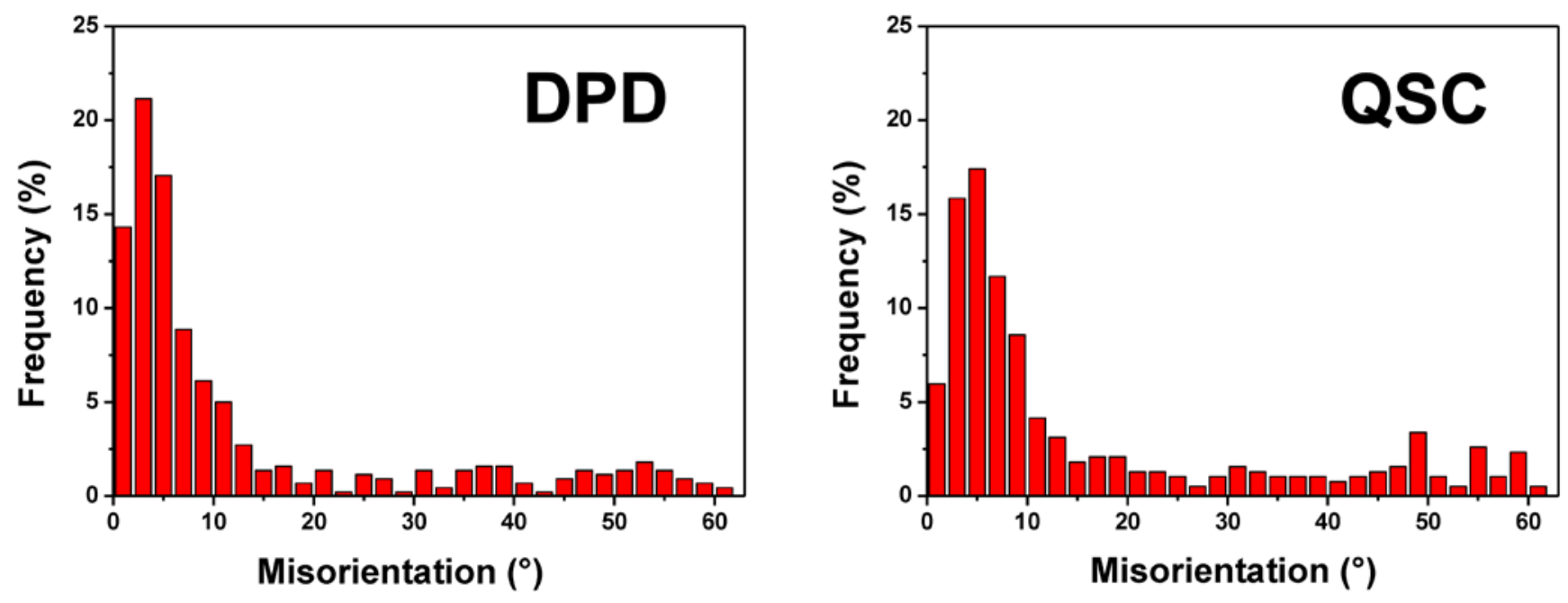

Figure 2. Distribution of boundary misorientation angles measured using TEM in the DPD and QSC samples.

Levels:
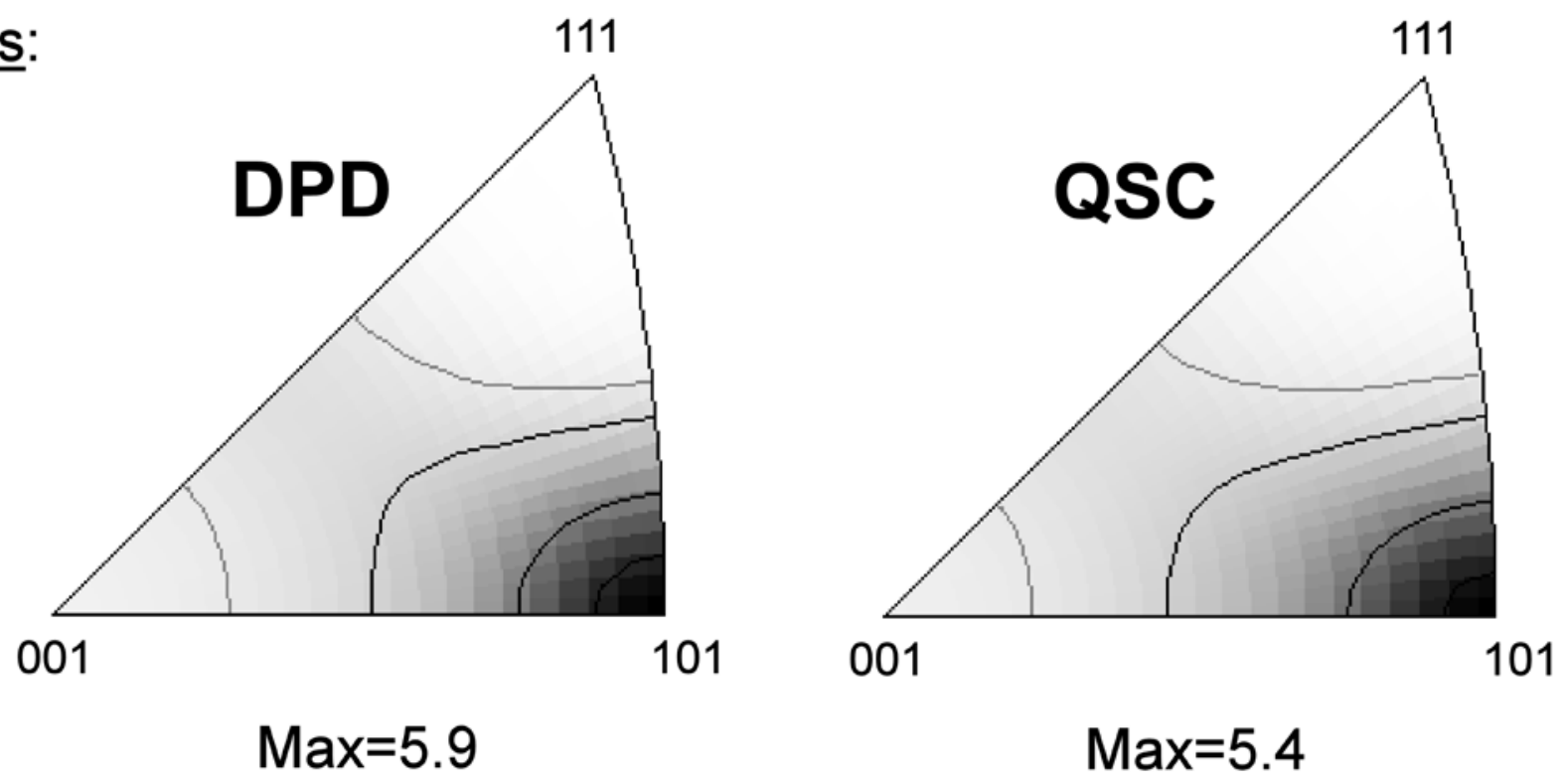

Figure 3. Textures in the DPD and QSC samples represented by inverse pole figures for the compression axis. 


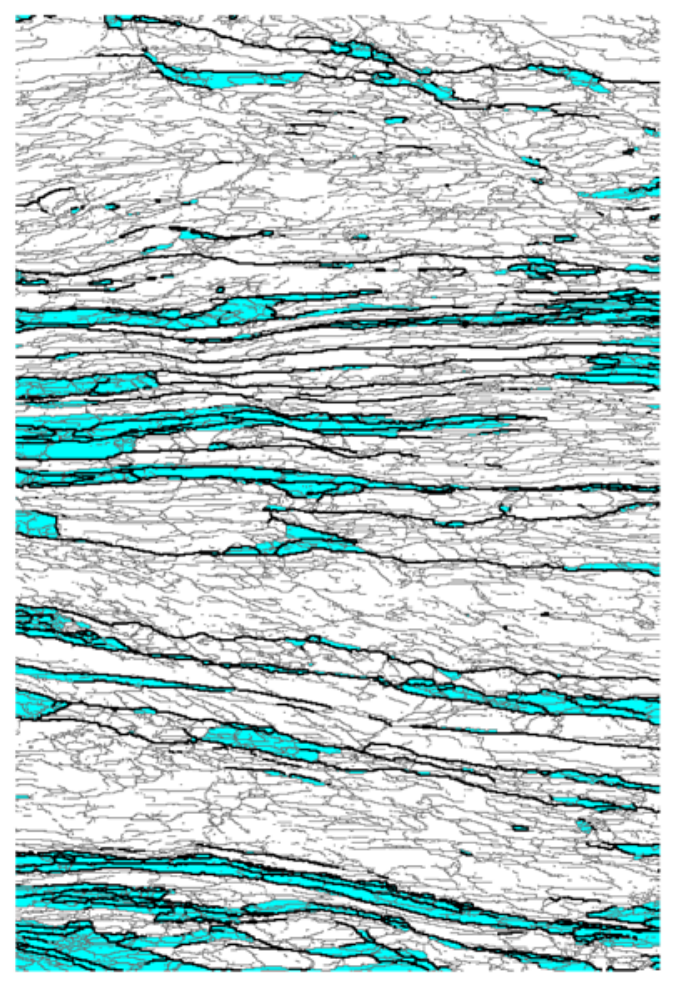

(a)

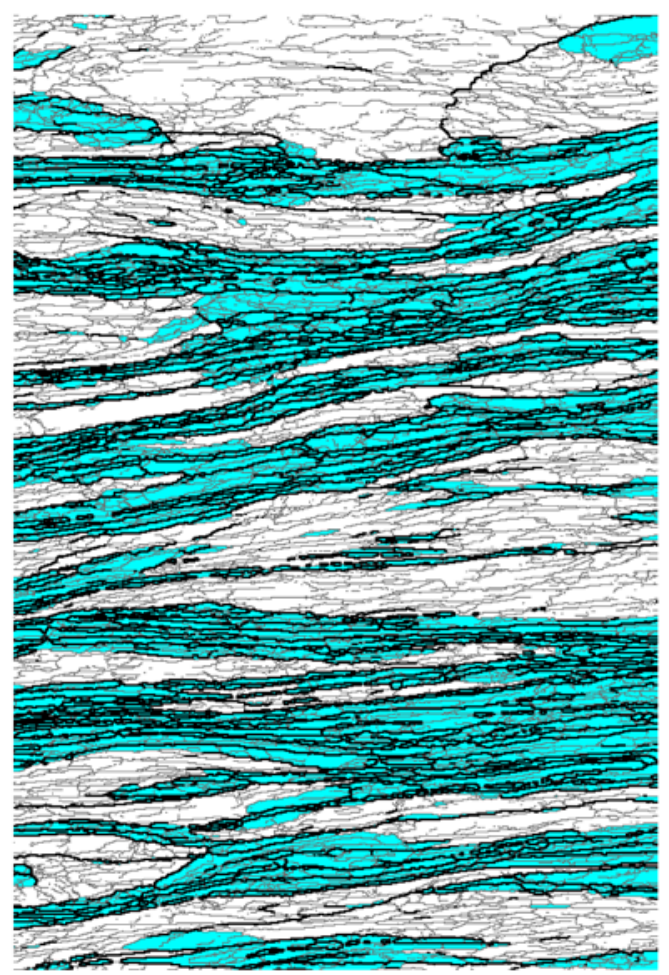

(b) $5 \mu \mathrm{m}$

Figure 4. EBSD maps from the DPD (a) and QSC (b) samples. Areas in cyan are HMRs. LMRs are not colored. Thin grey lines correspond to low $\left(1.5-15^{\circ}\right)$ misorientations. HABs are shown by bold black lines. 